\title{
Crioglobulinemia associada ao HCV
}

Farias, Bruna Brandão de; Hassan, Imman Fuad Khattab; Soares, Camila Tlustak; Böhlke, Maristela;

\section{RESUMO}

A crioglobulinemia pode apresentar-se como uma glomerulopatia associada ao vírus da hepatite $\mathrm{C}(\mathrm{HCV})$ e tem como característica a deposição de imunocomplexos em tecido renal. $\mathrm{O}$ relato refere-se a um paciente do sexo feminino, 36 anos, portadora do vírus HIV que buscou atendimento com sintomatologia de edema em membros inferiores, oliguria, febre, lesões cutâneas e hipertensão arterial. Em investigação diagnóstica foi detectada proteinúria em faixa nefrótica, hematúria, hipoalbuminemia e depuração da creatinina endógena estimada em $36 \mathrm{~mL} / \mathrm{min}$. Na investigação etiológica da glomerulopatia foram detectados anticorpos para vírus $\mathrm{C}$ da hepatite, crioglobulinas circulantes e redução das frações C3 e C4 do complemento. Esses achados levaram a hipótese diagnóstica de crioglobulinemia causada por hepatite $\mathrm{C}$ com acometimento renal. A paciente foi submetida a punção biópsia renal guiada por ultrassom para diagnóstico definitivo. $\mathrm{O}$ tratamento a ser implementado visa a remissão da doença de base, o HCV, por meio do protocolo preconizado pelo Ministério da Saúde: atualmente composto por sofosbuvir, simeprevir ou daclatasvir. Assim, é de grande importância a suspeita diagnóstica da crioglobulinemia, complicação rara mas potencialmente fatal do vírus $\mathrm{C}$ da hepatite, o que possibilita tratamento precoce e redução da morbimortalidade associada a condição. $\mathrm{O}$ relato objetiva demonstrar a relevância da investigação de sorologias virais em pacientes que se apresentam com quadro clínico de glomerulopatias. 